\title{
WORKING PAPER SERIES: PHILOSOPHY AND KNOWLEDGE: Reflexion on a flexible management method.
}

Purpose: Theoretical Discussion

ABSTRACT

In this discussion, we reflect on the value given to knowledge in a business context and deliberate a contrary philosophical perspective which does not conform to prevailing knowledge theory. We consider why, if knowledge is key for business success and competitive advantage, the transfer of knowledge within an organisation remains problematic. Whereby, if the creation of knowledge before transfer is recognised is a significant factor in determining a starting point for analogous scrutiny, then what makes this focal point so difficult to establish and measure?

We therefore consider parallelism between agents who believe propositions and the formal system that derives proposition. In doing so, we synthesise from current literature and research, the epistemic principal of 'knowledge', which underpins the understanding of the many congruent knowledge transfer theories, in a business context. To do this we reflect on Lindström and the epistemic states of Spohn, wherein, we can draw on descriptions of conditional doxastic maps, as a natural extension of contemporary Kripke models. We conclude the epistemic principle of 'knowledge', which underpins the plausibility of comparisons between epistemically distinguishable knowledge transfer, must include perspectives and doyennes from a recognisable, not implied, value standpoint. 


\section{Introduction}

For this discussion, we adopt a Hintikka (1962; 1963; 1982) logical [modal] operator as a useful predicate at the onset. This allows early establishment of an agent who believes it is possible to reason and represent aspects of beliefs regarding reality, from the frame of reference of the agent. Therefore, propositions in this discussion involving belief, knowledge and probability, assume elemental obligations, whereby, they become the appropriate actions of the agent ( Tajfel, 1978; Pick \& Lockman 1981; Kranjec, et al. 2012), and this allows us to maintain a business context within the core discussion (Marx, 1967;1978;1988; Weber,1925/1978). Moreover, to allow definitive axiomatisation, we recognise the logic of epistemic actions as a core aspect of this discussion, whereby, the altruistic cooperation and open conflict arena within an agent's frame of reference, form intermediate and multi-agent belief revisions (Kranjec, 2005).

This now becomes a very useful and pragmatic stating point, since it allows us to recognise interpretations of familiarity as elements of knowledge in an agent's interpretation of reality, particularly in the region of cooperative problem solving and decision making. This becomes a significant premise, since interpretation of this interaction could lead to a number of different or individual validity subscriptions or solicitations. Identification of this standpoint is also necessary so as not to coerce the discussion toward simplification of pluralistic leadership realms or modes of existence (Storsletten \& jakobsen, 2015). Similarly, distract us towards contemporarily established Popper (1968) - Renyi (1955) axioms, discussed by Boutilier, (1995) and expanded upon by Arlo-Costa \& Parikh (2005). Secondly, as a discussion intermediary, this can allow us to recognise the notion of a qualitative approach to a contemporary Kripke-model (Kripke 1959). This is important as a Kripke-style model proposes that specific quantitative mechanisms are the key elements by which multi-agent belief revision are based on.

\section{Overview}

We can now agree, or at least assume, plausible extensions and reciprocal elements of classical probability theory which now allow us to interpret belief revision(s) and correct probabilistic understanding(s) required by conditional beliefs (Segerberg, 1998; 1999). Consequently, simplification of context or category of meaning, possibilities and necessities becomes possible, wherein, 
plausibility tasks or probabilistic events become graded measures (Bennet, 2003). Whereby, allow us to interpret variations of classical belief revision theory, but intercede a multi-agent version. To underpin this simplistic, but interpretive stance, our discussion escalates the role and significance of validity (Fascia, 2015), within known knowledge transfer arenas (Argote et al. 2000) as this allows a foundation of significance to dominate any propositional inference. Additionally, it is perhaps unsurprising why interpretive positioning from contemporary literature leads to the view from (Dinur, 2011), who stresses that knowledge is a subjective perspective of an individual's experience, and therefore, associated problems from a business environment are linked to the context of the knowledge itself. Whereby, our discussion assumes an interpretive congruence as an explanatory position, and this central locus becomes key for knowledge interpretation as it provides a valid frame of reference. Importantly, at this stage, establishment of simplistic context or category of meaning allow us to inaugurate boundaries of possibilities and necessities which, would otherwise have remained an overly complex endeavour. To help us gain a simplistic focus regarding this complex phenomena, within this discussion, we suggest that that agent can establish a real time state of validity, that is, an internal locus or state of belief, whereby, all iterations of probability relating to the transfer dilemma remain as valid, only if they are logical along a constant frame of reality. Thus, in this assemble, set $\mathrm{G}$ can assume a classical consequence operation $\mathrm{Cn}$, wherein, the operation of expansion is concurrent with, and only with, the agent's reality frame of reference Kranjec, et al. 2012). Thus, we can deduce that any new information within this reality frame becomes and expansion of set $\mathrm{G}$, (current understanding of all available knowledge), but only from the agents frame of reference (reality). This view in itself becomes understandable if you also consider its interpretation of knowledge from the perspective of (Barnett at al., 2011). Their view indicates that an individual's past experiences related to knowledge can contribute to the retaining of knowledge, and, that personal resources may contribute to the current state of understanding.

\section{Business Context}

To assist with this complex interaction, key elements of emphasis can be drawn from a POPC lens approach (Fascia, 2015), since this approach allows a multi view perspective to interweave between individual and group interpretations within a linear frame of reference (Fascia, 2016). This approach allows us to consider that form and location of the knowledge, the 
indication of knowledge-sharing capability, the relationship between the source and the recipient and the broader environment in which the transfer occurs, are all contributive factors in assessing success (Fascia, 2015). This view now gives the observer a similar frame of reference to the participating agents, whereby, any revision of a proposition within the reference framework allows interpretation from a predicate. Hence, satisfy the necessary axioms, both by contradiction and revision, and at the same time, consider facets of congruence and consistency within the agent's interpretation Kranjec, et al. 2012).

If the position previously discussed is the universal norm within generalist business management theory (White \& Cicmil, 2016), then one could legitimately ask, if the existence of knowledge that in itself depends on the interpretation of a foundational normality is true. Wherein, does the relationship of belief under this premise result from epistemic incongruence by assuming it is either connected on unconnected to the propositional outcome. If this rational intuition were collective, then, all knowledge must derive from a consequence of foundational ethics, which themselves cannot be refuted by accepted moral norms.

This situation is perplexing to say the least and suggests that knowledge of the real world, particularly in a business context, is fallible and multifariously theory laden and allows several options when revising theory with a similar proposition, whereby, a willingness to accept presuppositions which is independent of any evidence. Thus, relating this position to knowledge value in a business context (White \& Cicmil, 2016), it is important to consider the different beliefs asymmetries (Jehn et al., 2015) to which practitioners, as human beings, hold in two very distinct ways. These are basic and non-basic. (Lambek \& American Mathematical Society., 2009). Regardless of indifference, there exists agreement within many research streams that organisational knowledge, even in this dissected form, is a recognised source of competitive advantage (Argote and Ingram 2000, p. 156; Storsletten \& jakobsen, 2015) and it is this centralisation of assumption, which can be used to underpin significance in an organisational context.

\section{Positioning}

Thus, this formalised position allows us to highlight principles, evident in current theoretical or conditional interpretations (Spohn ,1988) in the context of or surrounding knowledge transfer mechanisms. In doing so, easily relate these to practical and recognisable business environments. For example, leadership, discussed in detail by Storsletten \& 
jakobsen (2015). From this standpoint, we can then relate interpretation within an aperture of current thinking, wherein, theories of reality and change allow the formation of informal axiomatic theories of belief (Godel, 1932; Bull \& Krister 1984), and therefore, remain perpetual or dynamic within a knowledge transfer scenario in a business context. \{ There is not enough time or space in this short discussion to go into an in-depth conversation around constructive or non- constructive truths $\}$. However, unquestionably, it is only by analysing the somewhat complex processes which combine and surround daily working practices, that useful identification of normative and appropriate interaction between practitioners, during knowledge transfer, can be identified as useful or have value for an organisation. Nevertheless, analogous scrutiny at this point reflects egoistic formations of reality from a knowledge transfer practitioners perception, and can be thought of as a form of cautious belief (Rotaru et al., 2014) of any experience other than that relative to the knowledge transfer scenario. That is, continues to remain analogous to the knowledge transfer practitioner's experiential accounts of knowledge, but, would be unable to validate the putative distinctive value of knowledge at a single reference point.
Therefore, we can now understand that examination of knowledge taxonomy and the types of knowledge related to business, reveal the complex intertwining with necessary communication scenarios needed to transfer any notion of knowledge from both an observer and a participating agent or agents frame of reference (Kranjec, 2005). If we accept this posit as knowledge that is independent of all particular experiences, then it is also equally important to understand the significance of experiential reasoning behind this interpretive position of knowledge before it is transferred. Whereby, any argument to the contrary would become invalid to either party.

Thus, in this reality, any revision of proposition would result from the relationship between the two axioms and could be interpreted as measurement. We can now argue that this is a natural event, since the practitioners view of knowledge is subjective and assumes any possibly relevant mental states are experiential (Kranjec, 2005). Therefore, we could assume examination of an overriding epistemic principle as a required baseline for success critique. It is easy to understand why this simplistic view could be appealing and complete a natural enough answer for knowledge definition. However, this baseline would not relate to both business 
and personal savannas of existence, since knowledge from this perspective can only exist because someone knows it in his or her mind (Shukla, M., 2015). By definition, knowledge in this form is not an independent entity, which can be transferred, such as information surrounding any material object might be (Shukla, M., 2015). For example, a subject or phenomena within a normal sphere of reality cannot be transferred as knowledge, since it does not exist as independent knowledge.

\section{Construal}

For this discussion therefore, it is clear that a central locus of foundational realism (Peters et al, 2010) is somewhat important, and perhaps critical for the identification or interpretation surrounding the use of knowledge within an organisation, and certainly important if predicated by the wish to achieve and measure competitive advantage (Argote et al. 2000). Although generalisability of this positioning could, on the surface at least, appear rather simplistic, contemporary theory differs in many respects. Authors such as (Shukla, 2015) and (Evangelista \& Durst, 2015) for example, lament that a generally accepted working definition of knowledge for the organisational environment is yet to be established. In this regards, (Dinur, 2011) further advises that in addition to no agreed definition of knowledge within management literature, little in the way of commonality can be offered regarding consequent theoretical positioning. This is reiterated in recent work by (Rotaru, Churilov, \& Flitman, 2014) and (Donate \& Guadamillas, 2015), who suggest that problems with knowledge transfer in a business context remain prevalent, since in the main, knowledge is difficult to define, can be ambiguous, unspecific and a dynamic phenomenon. It remains difficult therefore, without the use of a logical structure, to deduce which assemblies of knowledge understanding support or interrupt emerging propositions, and which are simply a by-product from the interaction of the various actors involved in the transfer process (Rotaru, Churilov, \& Flitman, 2014).

Considering the previous text, it is perhaps understandable why many key authors focus on ways to comprehend and ultimately enhance this knowledge understanding in a business context, as it would appear to be a key factor in understanding useful attributes (White \& Cicmil, 2016). However, in doing so, this view would ultimately seek to examine various propositions using a single point of view, principally from occidental foci, 
which in itself is derived from historical concepts of Objectivism (Green, 2012). Therefore, we may consider this myopic interpretive stance as something, which contributes to the incredulity surrounding knowledge and is part of a non-existing logical context when deriving a reality (Stalnaker, 1968; Spohn ,1988). Consequently, the interpretive praxis for a specific knowledge schema could be debated at length as it would appear that there is no single interpretation of something, which could be interpreted as normal knowledge, even within the realms of contemporary thinking around critical realism (Bull \& Krister 1984; Rotaru et al., 2014). Ultimately, when considering a useful element to knowledge within an organisation, it would seem logical to consider how a position of identifiable knowledge fits within an agent's interpretive overview of formalised knowledge within general business management theory, and how they are interpreted as useful in that context. That is, we need to consider the reality of how and why an observer of a knowledge transfer scenario would consider sets of closely related realities with differing frames of reference Boutilier, (1995). This would result in a formal structure of the agent's belief and the ordering of epistemic propositions (Arlo-Costa \& Parikh ,2005).

\section{Measurable Impost}

If we are now able to consider this duality of proposition as a single entity, that is, to what extent can alignment be validated, in a way that supports corrective knowledge transfer axioms (Jiang, et al., 2015), then it becomes a very useful perspective indeed. This is because both positional inferences presuppose an assumption, in that, they both require interpretive associations from the actors to legitimise any validity regarding knowledge, and thus, inextricably link knowledge and knowledge transfer as the same cognitive process (Kranjec, 2005).

That is, differing actions align to differing options or operators of necessity, and not simply interpretations of fallible and defeasible evidence as experiential/nonexperiential. This is an important position to adopt, as we can now approach epistemological issues regarding the definition of knowledge and knowledge value from a pragmatic centre. However, we first need to be able to adopt an axiomatic starting point (Jiang, et al., 2015) and epistemic principle from which to define knowledge from multiple perspectives. The benefit from this interpretation is clear, that is, if we endorse this axiomatic positioning, then we can endorse both hermeneutics and foundationalism as a generality norm or 
singularity. That is, it becomes dynamic. Whereby, the represented states of external reality of the observer assume the agents position as not part of the observers reality frame. Whereby, the agent's dispositions do not align to his beliefs. Thus, his actions or change, cannot effect any part of any external reality.

In this case, we can now draw from definition by (Feenstra, 1988) and (Ahmad \& Daghfous, 2010), whereby, knowledge must consist, at least to a large extent, in a clarification of value which does not consist in definition alone, and therefore, must possess a systemic for such clarification using epistemic principle. As such, we can now agree that knowledge from this multivariate perspective exists as a combined state, but our awareness of it remains unclear, is singular in focus and suffers from borrowed interpretations covering many disciplines. In this sense, we can now understand why, although numerous in number, most theoretical interpretations belie the potentials inherent in focused research. Wherein, most attempts to categorise a temporal state for knowledge end up as a lateral presumption which, by its very nature, attempts to coexist with cognitive interpretations of knowledge. Therefore, it is easy to see why interpretations inevitably vary, are very broad and where non-specific boundaries and parameters pillory most, if not all, indices of symptomatic validity. To fully debate, this point would be extensive to say the least, however in the caveat of a business context, we can say that a philosophically identifiable position of knowledge is a phenomenon, which may be experienced as a temporal dimension, but has to be justified as a true belief before it can be termed valuable. Similarly, in this case, the construct of our knowledge is parallel to doxastic attitude as discussed previously. In this discussion, we can accept that from a business context, when conceiving as a faculty for distinguishing between truth and falsity, any experiential decision that would lack the cognitive status, traditionally ascribed, and therefore would be considered a priori false. Accordingly, from the standpoint of knowledge value, it is important to consider the evidence of this knowledge when deciding if it is true or not. As such, does the knowledge itself need to be better understood before it can be successfully transferred or is it simply empirical cogency, which has been transferred.

Clearly, from a business context, this involves philosophical support by paradigms and archetypes overarching business activity and relating to business success, but thereby giving knowledge 'value' by this premise alone and not as a 
justification of any other epistemic principle.

\section{CONCLUSION}

This discussion has focused on outlining and assessment of current and historical knowledge philosophy, theory and positioning, but at the same time, places it within the realms of a business context. In the discussion, we concentrated on a Doxastic attitude and epistemic principle surrounding the use of knowledge in a business context, wherein, we concluded that this combined faced becomes necessary when examining if knowledge is important. Through reconciliation of foundational and doxastic positions, one can now view knowledge and knowledge value as a singular construct. Importantly however, this is characterised through a multitude definition but not as a singular epistemic principle. Wherein, to assume any value or relevance to the sender or receiver, the acceptance of the tripartite theory of knowledge, Belief, Truth and Justification (epistemic principle) must also be inferred as a norm within the transfer mechanism. Therefore, give justification to the premise surrounding the interaction of an epistemic knowledge principle, based on a knowledge transfer practitioner's point of view supported by a doxastic presumption. This would now allow the identification of alternative perspectives to knowledge and knowledge transfer mechanisms. From the perspective of mainstream business management literature, and specifically relating to underpinning business practices of success and competitive advantage, this flexibility in interpretation becomes an advantage to the business or organisation. 
1. Ahmad, N., \& Daghfous, A. (2010). Knowledge sharing through inter-organizational knowledge networks. European Business Review, 22(2), 153-174.

2. Argote, L. and Ingram, P. (2000), "Knowledge transfer: a basis for competitive advantage in firms," Organizational Behaviour and Human Decision Processes, 82, 150-169.

3. Arlo-Costa, H \& Parikh, R. (2005). Conditional probability and defeasible inference.Journal of Philosophical Logic, 34:97-119

4. Barnett, J., Vasileiou, K., Djemil, F., Brooks, L., \& Young, T. (2011). Understanding innovators' experiences of barriers and facilitators in implementation and diffusion of healthcare service innovations: a qualitative study. BMC Health Services Research, 11, 342.

5. Bennett, J.(2003). A philosophical guide to conditionals. Oxford Univ. Press.

6. Boolos, George. (1993). The Logic of Provability, Cambridge: Cambridge University Press.

7. Boutilier, C. (1995). On the revision of probabilistic belief states. Notre Dame Journal of Formal Logic, 36(1):158-183

8. Bull, R. A. and Segerberg, Krister. (1984) "Basic Modal Logic", in Gabbay \& Guenthner Handbook of Philosophical Logic, 2: 188.

9. Dinur, A. (2011). Tacit Knowledge Taxonomy and Transfer: Case-Based Research. Journal of Behavioral and Applied Management, 12(3), 246-281.

10. Donate, M. J., \& Guadamillas, F. (2015). An empirical study on the relationships between knowledge management, knowledge-oriented human resource practices and innovation. Knowledge Management Research \& Practice, 13(2), 134-148.

11. Evangelista, P., \& Durst, S. (2015). Knowledge management in environmental sustainability practices of third-party logistics service providers. VINE, 45(4), 509-529.

12. Fascia, M (2015), "Understanding Dimensioning of Knowledge Transfer Perspectives using POPC", Journal of Management Studies and Economic Systems (MSES). Vol. 2, No. 2, Page 143-154. Autumn 2015.

13. Fascia, M (2016), "Linear notion of knowledge: A short Review, Journal of Multicultural Research (JSOE). Vol. 1, No. 1, p1-8. (ISSN 2058-5306)

14. Feenstra, R. J. (1988). Natural theology, epistemic parity, and unbelief. Modern Theology, 5, $1-12$.

15. Green, M. (2012). Objectivism in organization/management knowledge: an example of Bourdieu's "mutilation"? Social Responsibility Journal, 8(4), 495-510.

16. Gödel, Kurt. (1932). "Eine Interpretation des intuitionistischen Aussagenkalküls”,Ergebnisse eines mathematischen Kolloquiums 4: 3940.

17. Hintikka, J. (1962). Knowledge and Belief, Cornell University Press, Ithaca, New York.

18. Hintikka, J. (1963) “The Modes of Modality”, Acta Philosophica Fennica 16: 6582.

19. Hintikka, J. (1982). "Is Alethic Modal Logic Possible?”, Acta Philosophica Fennica 35: 
89105.

20. Jain, A. K., \& Moreno, A. (2015). Organizational learning, knowledge management practices and firm's performance. The Learning Organization, 22(1), 14-39.

21. Jehn, k. A., de wit, f. R. C., barreto, m. \& rink, f. 2015. Task conflict asymmetries: effects on expectations and performance. International journal of conflict management, 26, 172.

22. Jiang, Y., Colakoglu, S., Lepak, D. P., Blasi, J. R., \& Kruse, D. L. (2015). Involvement work systems and operational effectiveness: Exploring the moderating effect of national power distance. Journal of International Business Studies, 46(3), 332-354.

23. Kranjec, A. (2006). Extending spatial frames of reference to temporal concepts.Proceedings of the 28th Annual Conference of the Cognitive Science Society, 447-452.

24. Kranjec, A, Cardillo, E. Schmidt, G. Lehet M. \& Chatterjee A. (2012). Deconstructing Events: The Neural Bases for Space, Time, and Causality. Journal of Cognitive Neuroscience 24(1), 1-16.

25. Kripke, Saul. (1959). “A Completeness Theorem in Modal Logic”, Journal of Symbolic Logic 24:114.

26. Lambek, J., \& American Mathematical Society. (2009). Lectures on rings and modules. Providence, RI: AMS Chelsea Pub.

27. Lindström, St.; Rabinowicz, Wl. (1999). "DDL Unlimited. Dynamic Doxastic Logic for Introspective Agents". Erkenntnis 51 (2-3): 353-385

28. Marx, K. (1844/1988) Economic and Philosophic Manuscripts of 1844. Tr. Martin Milligan Amherst, NY: Prometheus Books.

29. Marx, K. (1967), Capital, vol. 1 International Publishers, New York. 24.

30. Marx, K. (1978), 'Wages, Labour and Capital' in R. Tucker (ed), The Marx and Engles Reader, Penguin, London.

31. Peters, K., Maruster, L. \& Jorna, R. J. (2010) Knowledge claim evaluation: a fundamental issue for knowledge management. Journal of Knowledge Management, 14(2), 243-257.

32. Pick, H.L. \& Lockman, J.J. (1981). From frames of reference to spatial representation. In L.S. Liben, A.H. Patterson, N. Newcombe (Eds), Spatial representation and behaviour across life span. New York: Academic Press.

33. Popper, K,R. (1968). The Logic of Scientific Discovery (revised Edition). London Hutchison,. First Ed. 1934.

34. Renyi, A. (1955) On a new axiomatic theory of probability. Acta Mathematica Academiae Scientiarum Hungaricae, 6:285-335,

35. Rotaru, K., Churilov, L., \& Flitman, A. (2014). Can critical realism enable a journey from description to understanding in operations and supply chain management? Supply Chain Management, 19(2), 117-125.

36. Shukla, M. (2015). An Introduction to Knowledge Utilization Capability and its Autopoietic Epistemological Domain. Journal of the Knowledge Economy, 6(4), 1001-1012.

37. Tajfel, H. (1978) "Social Categorization, Social Identity, and Social Comparison," in Henri Tajfel (ed.), Differentiation Between Social Groups, New York: Academic Press. pp.61-76.

38. W. Spohn. Ordinal conditional functions: A dynamic theory of epistemic states. In W.L. 
Harper, B.Skyrms (eds.), Causation in Decision, Belief Change and Statistics, vol. 2, 105 134. Reidel, Dordrecht,1988.

39. R.C. Stalnaker. A Theory of Conditionals. In N. Rescher (ed.), Studies in Logical Theory, Oxford,Blackwell, APQ Monograph No2, 1968.

40. Segerberg, K. (1998). Irrevocable Belief Revision in Dynamic Doxastic Logic. Notre Dame Journal of Formal Logic, 39, No 3, 287-306.

41. Segerberg, K. (1999). Default Logic as Dynamic Doxastic Logic. Erkenntnis, 50, 333-352.

42. Storsletten, v. M. \& jakobsen, o. D. 2015. Development of leadership theory in the perspective of kierkegaard's philosophy. Journal of business ethics, 128, 337-349.

43. Weber, M. (1925/1978) Economy and Society: An Outline of Interpretive Sociology. Tr. E. Fischoff. Guenther Roth and Claus Wittich (eds.), Berkeley: University of California Press

44. White, G. R. T., \& Cicmil, S. (2016). Knowledge acquisition through process mapping. International Journal of Productivity and Performance Management, 65(3), 302-323. 